\title{
The Proton Magnetic Resonance Spectrum of ${ }^{15} \mathrm{~N}-$ Pyrrole
}

\author{
ERKKI RAHKAMAa \\ Laboratory of Molecular Spectroscopy, Department of Physics, University of Oulu, Oulu, Finland \\ (Z. Naturforsch. 24 a, 2004-2009 [1969] ; received 22 September 1969) \\ A sub-spectral analysis of the high resolution proton magnetic resonance spectrum of ${ }^{15} \mathrm{~N}$-pyrrole \\ has been performed as an $\mathrm{AA}^{\prime} \mathrm{BB}^{\prime} \mathrm{CX}$ spin system. Absolute values of the proton-proton and nitro- \\ gen-proton couplings have been determined. It has also been concluded that all three nitrogen- \\ proton couplings are negative. The parameters found in the analysis of the PMR spectra of normal \\ and deuterated pyrroles, have also been briefly reported.
}

In recent years the PMR spectral parameters of pyrrole have been subject to constant study ${ }^{1-5}$. In all these investigations the unaccuracy of the protonproton couplings has remained comparatively large. On the one hand this is due to the overlapping of several lines in this deceptively simple spectrum, and, on the other hand, to the broadening of the lines caused by the quadrupolar relaxation of the ${ }^{14} \mathrm{~N}$ nucleus.

The effect of the latter factor can be diminished by lowering the temperature of the sample, and it can be completely eliminated either by using heteronuclear double resonance in producing the ${ }^{1} \mathrm{H}-\left\{{ }^{14} \mathrm{~N}\right\}$ spectrum, or by analysing the PMR spectrum of ${ }^{15} \mathrm{~N}$-pyrrole.

When studying the solvent effects of the PMR spectrum of pyrrole, the author of this paper found that there were still unaccuracies in the values of the proton-proton couplings he obtained through different methods ${ }^{6}$. In order to achieve more accurate values, the author decided to analyse the PMR spectrum of ${ }^{15} \mathrm{~N}$-pyrrole.

Contemporary to these measurements, KATEKAR and Moritz ${ }^{7}$ published their analyses on the PMR spectra of normal and deuterated pyrroles obtained using double and triple resonance technique with very high resolution.

The present work contains the sub-spectrum analysis of ${ }^{15} \mathrm{~N}$-pyrrole, which, beside giving the values of the proton-proton couplings, in addition gives the

Reprint requests to E. RaHKAMAa, Laboratory of Molecular Spectroscopy, Department of Physics, University of Oulu, Kontinkangas, Oulu, Finland.

1 R. J. Abraham and H. J. Bernstein, Can. J. Chem. 37, 1056 [1959] ; 39, 905 [1961].

2 S. Gronowitz, A. B. Hörnfeldt, B. Gestblom, and R. A. Hoffman, Arkiv Kemi 18, 133 [1961].

3 B. Dischler and G. Englert, Z. Naturforsch. 16 a, 1180 [1961]; 20 a, 888 [1965]. values for the couplings between the ${ }^{15} \mathrm{~N}$ nucleus and the protons. The parameters found in the analyses of the PMR spectra of normal and deuterated pyrroles, have also been briefly reported.

\section{Experimental}

The pyrrole used was a commercially available sample from Fluka AG, Zurich, Switzerland, purified by fractional distillation under low pressure.

The ${ }^{1} \mathrm{H}-\left\{{ }^{14} \mathrm{~N}\right\}$ spectrum has been recorded from pure pyrrole at room temperature using a JNM-C- $60 \mathrm{H}$ spectrometer with a JNM-SD-HB Heteronuclear Spin Decoupler from JEOL (Japan Electron Optics Laboratory Co., Ltd.). The observing frequency was $60 \mathrm{MHz}$ and the irradiation frequency 4.334 MHz. JEOL's JNM-4H-100 spectrometer equipped with JES-VT-3 temperature controller has been used at sample temperatures of $+40{ }^{\circ} \mathrm{C}$ and $-20{ }^{\circ} \mathrm{C}$ for recording the $100 \mathrm{MHz}$ spectra of pure pyrrole. These spectra have been recorded at both sweep directions using calibrated charts. The ${ }^{13} \mathrm{CH}$ satellite spectra were obtained from pure pyrrole using a Varian A-60 spectrometer and a C-1024 time averaging computer at $+33{ }^{\circ} \mathrm{C}$. The spectral line positions are averages of nine recordings.

The symmetrically deuterated $d_{4}$-pyrrole was prepared with the method described by BAK et al. ${ }^{8}$. The PMR spectra of $\mathrm{d}_{4}$-pyrrole were measured at $-24{ }^{\circ} \mathrm{C}$ on a Varian A-60 spectrometer and calibrated with a usual sideband technique using a Krohn-Hite 4100 oscillator and an Advance TC 4 counter.

${ }^{15} \mathrm{~N}$-pyrrole (96 per cent enriched) has been obtained from Isocommerz GMBH, Leipzig, DDR. The sample was degassed by tube to tube distillation under vacuum

4 Jeol News, 6 C (2), 3 [1968].

5 E. Rahkamaa, J. Chem. Phys. 48, 531 [1968].

${ }_{6}$ Phil. lic. thesis, May 1969, University of Oulu.

7 G. F. Katekar and A. G. Moritz, Aust. J. Chem. 22, 1199 [1969].

8 B. Bak, D. Christensen, L. Hansen, and J. Rastrup-AnDERSEN, J. Chem. Phys. 24, 720 [1956]. 
and sealed off in $5 \mathrm{~mm}$ o. d. sample tube. The PMR spectra have been measured at $+41{ }^{\circ} \mathrm{C}$ on a Varian A60 spectrometer operating at $60 \mathrm{MHz}$. All spectra have been calibrated by sideband modulation using a KrohnHite 4100 audio oscillator monitored constantly by an Advance TC 9 counter. The observed line positions are averages of three recordings at both sweep directions. The double irradiation experiments have been performed using frequency sweep on a Perkin Elmer R10 spectrometer equipped with a Spin Decoupling Accessory. The sample was a $d_{5}$-pyridine solution of ${ }^{15} \mathrm{~N}$-pyrrole in concentration of 0.1 mole fraction.

Computer analyses were performed with an IBM $360 / 30$ system. The ABCDEIT-program ${ }^{9}$, based on the iterative least-squares method proposed by Castellano and Bothner-By, is used for the spectrum analyses of ${ }^{15} \mathrm{~N}$-pyrrole.

\section{2. ${ }^{1} \mathrm{H}-\left\{{ }^{14} \mathrm{~N}\right\}$ Spectrum}

In the analysed spectrum there could be found thirteen separate components, four of them belonging to both $\mathrm{CH}$ quadruplets, and the other five to the NH quintuplet. Since the observed 13 components are an insufficient basis for usual iterative spectral analysis, a more elementary method had to be used. Starting with roughly estimated values of chemical shifts and couplings, three values of the chemical shifts were at first varied in order to achieve a satisfactory agreement between the experimental and the calculated $\mathrm{AA}^{\prime} \mathrm{BB}^{\prime} \mathrm{C}$ spectra. The comparison was performed by placing the calculated lines for both $\alpha$ - and $\beta$-positioned protons into four groups, and the lines for the $\mathrm{NH}$ proton into five groups, corresponding to the components observed. The intensity-weighted average frequencies which had been calculated for these groups, were compared with the frequencies of the components in the observed spectrum. To achieve the best possible agreement all the six couplings were varied, at the same time giving the chemical shifts their final settings. The sum of squares of the deviations was used as a measure of agreement. This analysis gave the values of parameters collected in Table 1 .

\begin{tabular}{llcl}
\hline$J_{12}=J_{15}=2.6 \pm 0.1$ & $J_{23}=J_{45}=2.9 \pm 0.2$ \\
$J_{13}=J_{14}=2.5 \pm 0.1$ & $J_{24}=J_{35}=1.2 \pm 0.2$ \\
$J_{25}=$ & $2.0 \pm 0.3$ & $J_{34}=$ & $3.6 \pm 0.3$ \\
$\delta_{\alpha \beta}=$ & $0.17 \pm 0.01$ & $\delta_{\beta \mathrm{NH}}=$ & $1.10 \pm 0.01$
\end{tabular}

Table 1. Proton-proton couplings (in $\mathrm{Hz}$ ) and internal chemical shifts (in ppm) of pure pyrrole with estimated error limits.

9 J. Jokisaari and A. Sirkaluoma, to be published in Suomen Kemistilehti.

\section{CH Proton Spectra at $+40{ }^{\circ} \mathrm{C}$ and $-20{ }^{\circ} \mathrm{C}$}

The $\mathrm{CH}$ signals measured at $100 \mathrm{MHz}$ are composed of two four-component groups. The components of the spectrum recorded at $-20^{\circ} \mathrm{C}$ are narrower than those in the spectrum recorded at $+40{ }^{\circ} \mathrm{C}$. The spectra were analysed as described in the previous chapter. The obtained chemical shifts and proton-proton couplings are collected in Table 2.

\begin{tabular}{lll}
\hline & $+40{ }^{\circ} \mathrm{C}$ & $-20^{\circ} \mathrm{C}$ \\
\hline$J_{12}$ & $2.7 \pm 0.1$ & $2.7 \pm 0.1$ \\
$J_{13}$ & $2.4 \pm 0.1$ & $2.4 \pm 0.1$ \\
$J_{23}$ & $2.7 \pm 0.2$ & $2.5 \pm 0.2$ \\
$J_{24}$ & $1.3 \pm 0.2$ & $1.5 \pm 0.2$ \\
$J_{25}$ & $1.9 \pm 0.2$ & $2.1 \pm 0.2$ \\
$J_{34}$ & $3.6 \pm 0.2$ & $3.9 \pm 0.2$ \\
$\delta_{\alpha \beta}$ & $0.20 \pm 0.01$ & $0.12 \pm 0.01$ \\
$\delta_{\beta \mathrm{NH}}$ & $1.13 \pm 0.01$ & $0.94 \pm 0.01$ \\
\hline
\end{tabular}

Table 2. Couplings (in $\mathrm{Hz}$ ) and chemical shifts (in ppm) with estimated error limits found for pure pyrrole at temperatures of $+40{ }^{\circ} \mathrm{C}$ and $-20^{\circ} \mathrm{C}$.

\section{4. ${ }^{13} \mathrm{CH}$ Satellite Spectrum}

The carbon isotope ${ }^{13} \mathrm{C}$ in its normal abundance in pure pyrrole causes ${ }^{13} \mathrm{CH}$ satellites, among which the ones on the lower applied field are distinctly separate from each other. They can be interpreted as $\mathrm{X}$ parts in the ABCDX proton spectrum. The distances of the outer components in both satellite spectra correspond to the sums of the four protonproton couplings $J_{\mathrm{AX}}+J_{\mathrm{BX}}+J_{\mathrm{CX}}+J_{\mathrm{DX}}$. The measurements at $+33^{\circ} \mathrm{C}$ give the following results:

$$
\text { and } \quad \begin{aligned}
J_{23}+J_{24}+J_{25}+J_{12} & =(8.6 \pm 0.1) \mathrm{Hz} \\
J_{23}+J_{24}+J_{34}+J_{13} & =(9.8 \pm 0.2) \mathrm{Hz} .
\end{aligned}
$$

\section{PMR Spectrum of Symmetric $d_{4}$-Pyrrole at $-24^{\circ} \mathrm{C}$}

Protonation of $d_{5}$-pyrrole into $d_{4}$-pyrrole gives a sample which, beside the desired product, contains small amounts of pyrroles with additional protons. This can be verified by comparing the PMR spectrum of the acquired product to the calculated spectra of the pyrroles deuterated in different ways. $\mathrm{CH}_{\alpha}$ and $\mathrm{CH}_{\beta}$ protons of this sample produce in the spectrum recorded at $-24{ }^{\circ} \mathrm{C}$ two doublets, which give the following proton-proton couplings:

$J_{12}=(2.55 \pm 0.05) \mathrm{Hz}$ and $J_{13}=(2.35 \pm 0.05) \mathrm{Hz}$. 


\section{PMR Spectrum of ${ }^{15}$ N-Pyrrole}

\subsection{Analysis of the Spectrum}

The $1 / 2$-spin nuclei of ${ }^{15} \mathrm{~N}$-pyrrole form a 6 -spin system. Labelling the nuclei as given beside, the spectrum can be treated as an $\mathrm{AA}^{\prime} \mathrm{BB}^{\prime} \mathrm{CX}$ spectrum. The $\mathrm{AA}^{\prime} \mathrm{BB}^{\prime}$ part of this spectrum is given in Fig. 1 (a) and the two quintuplets of the $\mathrm{C}$ part in Fig. 2 (a) and (c). The spectrum obtained was interpreted using sub-spectrum analysis ${ }^{10}$.

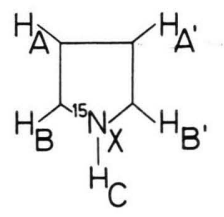

Since $J_{\mathrm{AX}}=J_{\mathrm{A}^{\prime} \mathrm{X}}$ and $J_{\mathrm{BX}}=J_{\mathrm{B}^{\prime} \mathrm{X}}$ the effect of the ${ }^{15} \mathrm{~N}$ nucleus on the $\mathrm{AA}^{\prime} \mathrm{BB}^{\prime} \mathrm{C}$ proton spectrum is equivalent to replacing the Larmor frequencies $v_{\mathrm{A}}=v_{\mathrm{A}^{\prime}}, v_{\mathrm{B}}=v_{\mathrm{B}^{\prime}}$, and $v_{\mathrm{C}}$ by effective frequencies ${ }^{11}$

$$
\begin{aligned}
& v_{\mathrm{A}}^{*}=v_{\mathrm{A}} \pm J_{\mathrm{AX}} / 2, \\
& v_{\mathrm{B}}^{\star}=v_{\mathrm{B}} \pm J_{\mathrm{BX}} / 2, \\
& v_{\mathrm{C}}^{*}=v_{\mathrm{C}} \pm J_{\mathrm{CX}} / 2,
\end{aligned}
$$

Accordingly the observed $\mathrm{AA}^{\prime} \mathrm{BB}^{\prime} \mathrm{CX}$ spectrum is a superposition of two $\mathrm{AA}^{\prime} \mathrm{BB}^{\prime} \mathrm{C}$ sub-spectra produced with frequencies corresponding the $+1 / 2$ and $-1 / 2$ spin values of the ${ }^{15} \mathrm{~N}$ nucleus. In order to find the relative signs for the couplings $J_{\mathrm{AX}}, J_{\mathrm{BX}}$, and $J_{\mathrm{CX}}$, the sub-spectra have been calculated with all the eight spin combinations of $J_{i \mathrm{X}}$. Among these the best agreement with the experimental spectrum give the two sub-spectra I and II, in which all the couplings $J_{i \mathrm{X}}$ have the same sign. The proton-proton couplings have been in all calculations here assumed to be positive.

The NH proton quintuplet in the lower applied field and the two lowest-field line groups of both $\mathrm{CH}_{\alpha}$ and $\mathrm{CH}_{\beta}$ protons belong to the sub-spectrum I. The higher-field NH quintuplet as well as the two highest-field line groups of $\mathrm{CH}_{\alpha}$ and $\mathrm{CH}_{\beta}$ protons arise entirely from the sub-spectrum II. This is confirmed by double resonance experiments. Only the components corresponding to the highest and lowest

10 P. Diehl, R. K. Harris, and R. G. Jones, in: Progress in Nuclear Magnetic Resonance Spectroscopy, Vol. 3 (ed. J. W. Emsley, J. Feeney, and L. H. Sutcliffe), Pergamon Press, Oxford 1967, p. 1. frequencies of the lower-field $\mathrm{NH}$ quintuplet were perturbed when the second and third $\mathrm{CH}_{\alpha}$ line groups were irradiated. This proves that the disturbed NH lines have a common energy level with the lines belonging to these $\mathrm{CH}_{\alpha}$ line groups. Similarly the higher-field $\mathrm{NH}$ quintuplet was perturbed, the lower-field quintuplet remaining unperturbed, when the highest-field line of $\mathrm{CH}_{\beta}$ protons was irradiated.

\subsection{Results}

In Table 3 appear the positions of lines derived as averages from the experimental spectra, as well as the lines and intensities belonging to sub-spectra I and II, which have been calculated with the parameters given in Table 4. The sub-spectra I and II are presented in Fig. $1(\mathrm{~b})$ and (c), and $2(\mathrm{~d})$ and (b). The agreement between the experimental and calculated spectra is illustrated by the differences $v_{\text {obs }}-v_{\text {calc }}$, which generally remain smaller than $\pm 0.10 \mathrm{~Hz}$. The values for proton-proton couplings and chemical shifts given in Table 4, are derived as averages through separate analyses of sub-spectra I and II. The absolute values of couplings $J_{i \mathrm{X}}$ given in Table 4 are calculated as differences

$$
\left|v_{i}^{*}(\mathrm{I})-v_{i}^{*}(\mathrm{II})\right|
$$

through the values of effective Larmor frequencies in sub-spectra I and II.

\subsection{Discussion}

The inaccuracy of the obtained couplings is mainly due to the inaccuracy in the locating of the lines of the spectrum, which is shown by the fact that the line positions obtained from the spectra recorded in both directions do not generally differ from the average value by more than $\pm 0.1 \mathrm{~Hz}$. The greatest difference between the values of protonproton couplings $J_{12}, J_{13}$ and $J_{25}$ in Table 4 and those given separately by the sub-spectra I and II is $\pm 0.01 \mathrm{~Hz}$. The values of couplings $J_{23}$ and $J_{24}$, derived from sub-spectra I and II, differ from those given in Table 4 by $\pm 0.08 \mathrm{~Hz}$, but in both subspectra the sum $J_{23}+J_{24}$ is $4.12 \mathrm{~Hz}$, which, in error limits, is equivalent to $4.15 \mathrm{~Hz}$, measured by KATEKAR and MORITZ ${ }^{7}$. The values for the coupling $J_{34}$

11 P. Diehl and J. A. Pople, Mol. Phys. 3, 557 [1960]. 


\begin{tabular}{|c|c|c|c|c|c|c|c|}
\hline $\begin{array}{l}\text { Obs. } \\
\text { Freq. }\end{array}$ & $\begin{array}{l}\text { Sub S } \\
\text { Calc. } \\
\text { Freq. }\end{array}$ & $\begin{array}{l}\text { I } \\
\text { Calc. } \\
\text { Int. }\end{array}$ & $\begin{array}{l}\text { Difference } \\
\boldsymbol{v}_{\mathrm{obs}}-\boldsymbol{v}_{\text {calc }}\end{array}$ & $\begin{array}{l}\text { Obs. } \\
\text { Freq. }\end{array}$ & $\begin{array}{l}\text { Spectr } \\
\text { Calc. } \\
\text { Freq. }\end{array}$ & $\begin{array}{l}\text { Calc. } \\
\text { Int. }\end{array}$ & $\begin{array}{l}\text { Difference } \\
v_{\text {obs }}-v_{\text {calc }}\end{array}$ \\
\hline 135.84 & 135.85 & 1.34 & -0.01 & 141.16 & 141.23 & 1.32 & -0.07 \\
\hline 135.53 & 135.51 & 1.43 & 0.02 & 140.84 & 140.86 & 1.40 & -0.02 \\
\hline- & 135.31 & 0.17 & - & - & 140.80 & 0.15 & - \\
\hline 133.73 & 133.81 & 1.76 & -0.08 & 139.01 & 139.13 & 1.70 & -0.12 \\
\hline 133.73 & 133.73 & 1.81 & 0 & 139.01 & 139.04 & 1.73 & -0.03 \\
\hline 133.73 & 133.71 & 1.66 & 0.02 & 139.01 & 139.04 & 1.59 & -0.03 \\
\hline 133.27 & 133.39 & 1.39 & -0.12 & 138.66 & 138.77 & 1.49 & -0.11 \\
\hline 133.27 & 133.26 & 1.79 & 0.01 & 138.66 & 138.69 & 1.69 & -0.03 \\
\hline 133.27 & 133.09 & 1.48 & 0.18 & 138.66 & 138.52 & 1.58 & 0.14 \\
\hline- & 132.82 & 0.18 & - & - & 138.12 & 0.20 & $\infty$ \\
\hline 131.71 & 131.70 & 2.58 & 0.01 & 137.07 & 136.99 & 2.39 & 0.08 \\
\hline- & 131.66 & 0.30 & - & - & 136.93 & 0.26 & - \\
\hline 131.36 & 131.48 & 2.77 & -0.12 & 136.77 & 136.86 & 2.51 & -0.09 \\
\hline 131.36 & 131.36 & 1.82 & 0 & 136.77 & 136.75 & 1.98 & 0.02 \\
\hline 131.36 & 131.32 & 1.88 & 0.04 & 136.77 & 136.74 & 1.94 & 0.03 \\
\hline 131.36 & 131.28 & 1.72 & 0.08 & 136.77 & 136.70 & 1.80 & 0.07 \\
\hline 130.87 & 130.78 & 1.86 & 0.09 & 136.13 & 136.13 & 1.96 & 0 \\
\hline 129.32 & 129.29 & 2.69 & 0.03 & - & 134.71 & 0.34 & - \\
\hline- & 129.24 & 0.32 & - & 134.68 & 134.70 & 2.80 & -0.02 \\
\hline 129.09 & 129.01 & 2.90 & 0.08 & 134.40 & 134.37 & 3.02 & 0.03 \\
\hline- & 128.24 & 0.07 & - & - & 133.73 & 0.06 & - \\
\hline- & 126.40 & 0.07 & - & - & 130.96 & 0.07 & - \\
\hline - & 125.72 & 0.07 & - & - & 130.74 & 0.06 & - \\
\hline - & 123.93 & 0.07 & - & - & 128.51 & 0.07 & - \\
\hline 123.13 & 123.15 & 2.76 & -0.02 & 127.55 & 127.52 & 2.16 & 0.03 \\
\hline- & 122.95 & 0.30 & - & 127.55 & 127.50 & 2.37 & 0.05 \\
\hline 122.84 & 122.94 & 2.57 & -0.10 & - & 127.36 & 0.25 & - \\
\hline 121.35 & 121.41 & 1.79 & -0.06 & 125.95 & 125.91 & 1.58 & 0.04 \\
\hline 120.87 & 120.90 & 1.80 & -0.03 & 125.27 & 125.43 & 1.59 & -0.16 \\
\hline 120.87 & 120.90 & 1.65 & -0.03 & 125.27 & 125.25 & 1.51 & 0.02 \\
\hline 120.87 & 120.82 & 1.76 & 0.05 & 125.27 & 125.23 & 1.62 & 0.04 \\
\hline 120.57 & 120.65 & 2.91 & -0.08 & 125.27 & 125.16 & 3.16 & 0.11 \\
\hline- & 120.44 & 0.32 & - & - & 124.88 & 0.35 & - \\
\hline 120.32 & 120.36 & 2.70 & -0.04 & 124.82 & 124.75 & 3.03 & 0.07 \\
\hline- & 119.36 & 0.17 & - & - & 123.80 & 0.14 & - \\
\hline 119.06 & 119.12 & 1.42 & -0.06 & 123.67 & 123.61 & 1.31 & 0.06 \\
\hline 118.72 & 118.85 & 1.87 & -0.13 & 123.13 & 123.24 & 2.07 & -0.11 \\
\hline 118.72 & 118.79 & 1.34 & -0.07 & 123.13 & 123.17 & 1.27 & -0.04 \\
\hline 118.26 & 118.40 & 1.73 & -0.14 & 122.84 & 122.89 & 1.89 & -0.05 \\
\hline 118.26 & 118.34 & 1.88 & -0.08 & 122.84 & 122.79 & 2.02 & 0.05 \\
\hline 118.26 & 118.30 & 1.83 & -0.04 & 122.84 & 122.72 & 2.12 & 0.12 \\
\hline- & 116.81 & 0.18 & - & - & 121.24 & 0.22 & - \\
\hline 116.52 & 116.57 & 1.48 & -0.05 & 120.87 & 120.95 & 1.67 & -0.08 \\
\hline 116.25 & 116.27 & 1.39 & -0.02 & 120.57 & 120.74 & 1.54 & -0.17 \\
\hline 13.66 & 13.63 & 1.09 & 0.03 & 110.01 & 109.94 & 1.52 & 0.07 \\
\hline 11.16 & 11.20 & 1.05 & -0.04 & 107.61 & 107.61 & 1.16 & 0 \\
\hline 11.16 & 11.17 & 1.05 & -0.01 & 107.61 & 107.61 & 1.29 & 0 \\
\hline 11.16 & 11.13 & 1.04 & 0.03 & 107.61 & 107.48 & 1.27 & 0.13 \\
\hline 11.16 & 11.05 & 1.04 & 0.11 & 107.19 & 107.17 & 1.08 & 0.02 \\
\hline 8.65 & 8.74 & 1.01 & -0.09 & 105.12 & 105.25 & 1.00 & -0.13 \\
\hline 8.65 & 8.70 & 1.00 & -0.05 & 105.12 & 105.14 & 1.09 & -0.02 \\
\hline 8.65 & 8.65 & 1.00 & 0 & 105.12 & 105.06 & 0.98 & 0.06 \\
\hline 8.65 & 8.64 & 1.00 & 0.01 & 104.86 & 104.94 & 0.95 & -0.08 \\
\hline 8.65 & 8.60 & 1.00 & 0.05 & 104.86 & 104.83 & 0.86 & 0.03 \\
\hline 8.65 & 8.55 & 0.99 & 0.10 & 104.86 & 104.78 & 0.94 & 0.08 \\
\hline 6.15 & 6.23 & 0.96 & -0.08 & 102.50 & 102.72 & 0.86 & -0.22 \\
\hline 6.15 & 6.18 & 0.96 & -0.03 & 102.50 & 102.57 & 0.76 & -0.07 \\
\hline 6.15 & 6.14 & 0.96 & 0.01 & 102.50 & 102.48 & 0.82 & 0.02 \\
\hline 6.15 & 6.08 & 0.95 & 0.07 & 102.50 & 102.34 & 0.75 & 0.16 \\
\hline 3.68 & 3.67 & 0.92 & 0.01 & 100.00 & 100.06 & 0.67 & -0.06 \\
\hline
\end{tabular}

Table 3. The observed and calculated spectra of ${ }^{15} \mathrm{~N}$-pyrrole. The origin of the frequency scale is arbitrarily chosen. The first line of the high field NH quintuplet [Fig. 2 (a) and (b)] was set to $100.00 \mathrm{~Hz}$. 

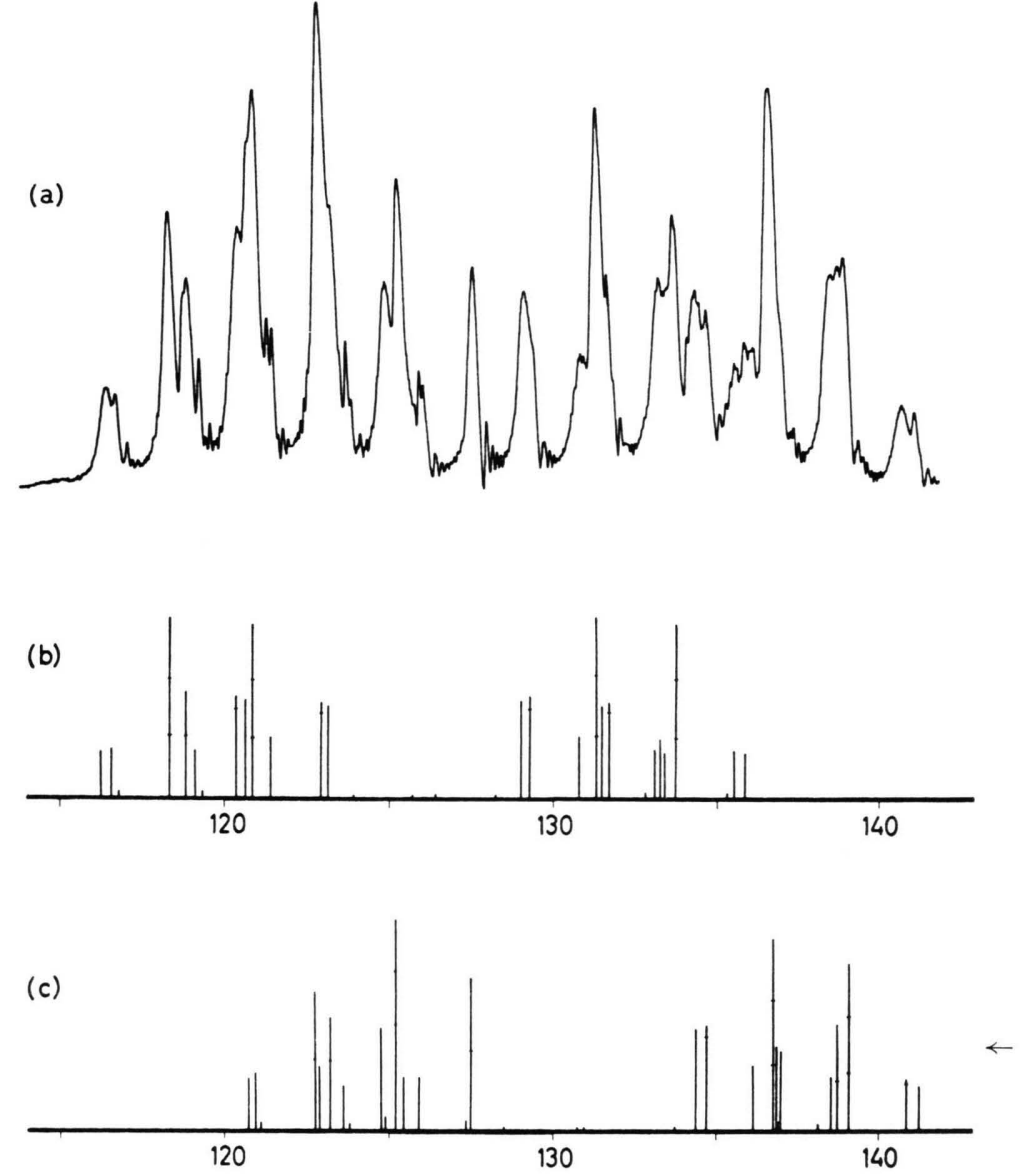

(a)

(b)
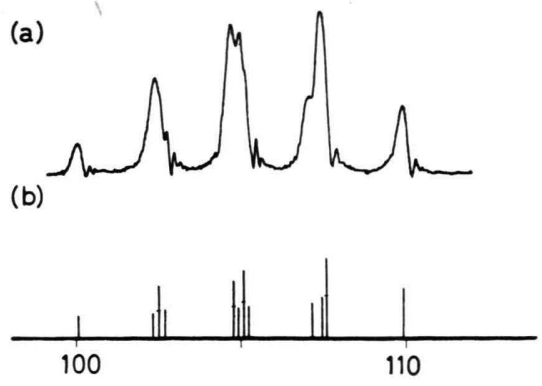

(c)

(d)

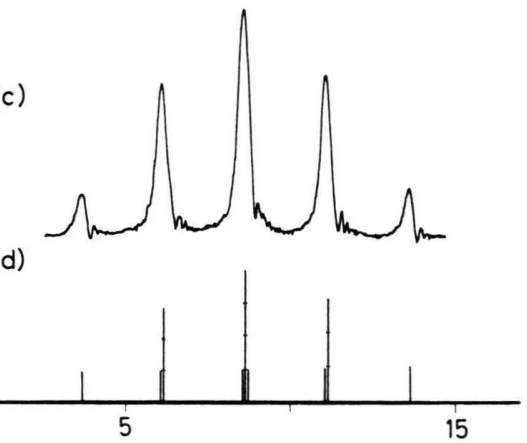

Fig. 2. (a) The observed higher-field $\mathrm{NH}$ quintuplet, (b) the calculated $\mathrm{C}$ part of the sub-spectrum II, (c) the observed lower-field the sub-spectrum I.

Fig. 1. The $\mathrm{AA}^{\prime} \mathrm{BB}^{\prime}$ part arising from the $\mathrm{CH}_{\alpha}$ and $\mathrm{CH}_{\beta}$ protons of ${ }^{15} \mathrm{~N}$-pyrrole. (a) The observed spectrum, (b) the calculated sub-spectrum I, (c) the calculated sub-spectrum II. given by the sub-spectra I and II differ from the average in Table 4 by $\pm 0.03 \mathrm{~Hz}$.

\begin{tabular}{crlr}
\hline & $\mathrm{Hz}$ & & \multicolumn{1}{c}{$\mathrm{Hz}$} \\
\hline$J_{12}$ & 2.53 & $v_{\mathrm{A}}{ }^{*}(\mathrm{I})$ & 132.21 \\
$J_{13}$ & 2.45 & $v_{\mathrm{B}}{ }^{*}(\mathrm{I})$ & 119.91 \\
$J_{23}$ & 2.71 & $v_{\mathrm{C}}{ }^{*}(\mathrm{I})$ & 8.70 \\
$J_{24}$ & 1.41 & $v_{\mathrm{A}}{ }^{*}(\mathrm{II})$ & 137.56 \\
$J_{25}$ & 1.98 & $v_{\mathrm{B}}{ }^{*}(\mathrm{II})$ & 124.27 \\
$J_{34}$ & 3.56 & $v_{\mathrm{C}}{ }^{*}(\mathrm{II})$ & 105.26 \\
$1 J_{\mathrm{NH}}$ & 96.56 & $v_{\mathrm{A}}$ & 134.89 \\
$2 J_{\mathrm{NH}}$ & 4.36 & $v_{\mathrm{B}}$ & 122.09 \\
$3 J_{\mathrm{NH}}$ & 5.35 & $v_{\mathrm{C}}$ & 56.98 \\
\hline
\end{tabular}

Table 4. Spectral parameters of ${ }^{15} \mathrm{~N}$-pyrrole obtained from the sub-spectrum analysis.

The effective Larmor frequency differences

$$
\left|v_{i}^{*}(\mathrm{I})-v_{i}^{*}(\mathrm{II})\right|
$$

12 J. P. Kintzinger and J. M. Lehn, Mol. Phys. 14, 133 [1968].

13 D. Crépaux, J. M. Lehn, and R. R. Dean, Mol. Phys. 16, 225 [1969]. give the values $\left|{ }^{1} J_{\mathrm{NH}}\right|=96.56 \mathrm{~Hz},\left|{ }^{2} J_{\mathrm{NH}}\right|=4.36 \mathrm{~Hz}$, and $\left|{ }^{3} J_{\mathrm{NH}}\right|=5.35 \mathrm{~Hz}$. The first of them can be compared to the value $97.5 \pm 1.4 \mathrm{~Hz}$, previously calculated through shape analysis of the ${ }^{14} \mathrm{NH}$ proton signal in normal pyrrole ${ }^{5}$. The two latter values may be compared with the couplings of $\mathrm{sp}^{2}$-hybridized nitrogen $\left|{ }^{2} J_{\mathrm{NH}}\right|=2.0 \mathrm{~Hz}$ and $\left|{ }^{3} J_{\mathrm{NH}}\right|=4.5 \mathrm{~Hz}$, which have been measured for protonated quinoline ${ }^{12}$.

In all the investigations made so far the coupling ${ }^{3} J_{\mathrm{NH}}$ has been found to be negative ${ }^{13}$. Furthermore, the couplings ${ }^{2} J_{\mathrm{NH}}$ and ${ }^{3} J_{\mathrm{NH}}$ of $\mathrm{sp}^{2}$-hybridized nitrogen have been found to have the same negative sign in quinoline both in the parent free base and in its protonated form ${ }^{13},{ }^{14}$. Accordingly it is most probable that also the coupling ${ }^{3} J_{\mathrm{NH}}$ of $\mathrm{sp}^{2}$-hybridized nitrogen in pyrrole is negative. Since the present

${ }^{14}$ K. Tori, M. Ohtsuru, T. Aono, Y. Kawazoe, and M. Ohnishi, J. Am. Chem. Soc. 89, 2765 [1967]. 
work shows that all the couplings $J_{\mathrm{NH}}$ have the same sign, the couplings ${ }^{1} J_{\mathrm{NH}},{ }^{2} J_{\mathrm{NH}}$, and ${ }^{3} J_{\mathrm{NH}}$ in pyrrole seem to be negative.

The values of the proton-proton couplings determined in this work with different methods are in reasonable agreement with each other. However, the inaccuracy in the values determined at temperatures of $+40^{\circ} \mathrm{C}$ and $-20{ }^{\circ} \mathrm{C}$ is so large that it is not possible to draw any conclusions upon the temperature effect on the proton-proton couplings ${ }^{15}$.

The results in this work prove in accordance with most of the earlier investigations ${ }^{2,3,7}$ that

$$
\left|J_{12}\right|>\left|J_{13}\right| \text {. }
$$

The spectrum is comparatively insensitive to the changes in the values of $J_{23}$ and $J_{24}$ when the sum $J_{23}+J_{24}$ stays in the range $4.0-4.1 \mathrm{~Hz}$. Therefore the precise determination of these two couplings is difficult. The obtained values for $J_{25} 1.9-2.0 \mathrm{~Hz}$ agree with the earlier investigations ${ }^{2-4,7}$. Though all the three measurements carried out at room temperature produce the same result $J_{34}=3.6 \mathrm{~Hz}$, it is not too accurate due to similar reasons as in the case of $J_{23}$ and $J_{24}$. The two investigations of the PMR spectrum of unsubstituted pyrrole published earlier ${ }^{3,4}$ suggest the values of $(3.7 \pm 0.2) \mathrm{Hz}$ and $3.6 \mathrm{~Hz}$ for $J_{34}$, whereas the latest one ${ }^{7}$ reports the value of $(3.34 \pm 0.05) \mathrm{Hz}$.
One of the two sums of four couplings (8.6 \pm 0.1$)$ $\mathrm{Hz}$ obtained from the ${ }^{13} \mathrm{CH}$ satellites agrees well with the ones determined at room temperature in this research and with those presented by other authors $^{3,7}$. The other one, $(9.8 \pm 0.2) \mathrm{Hz}$, is close to the sum $9.92 \mathrm{~Hz}$ calculated from the couplings reported by KATEKAR and MORITZ ${ }^{7}$. However, it is lower than the sum calculated from the couplings reported in this and the other works.

\section{Acknowledgements}

The author wish to thank Prof. P. TUомікоsкi for valuable discussions and Mr. J. JokISAARI for ABCDEIT-program. He is also grateful to Prof. G. BERGSON (University of Umeå, Sweden) for allowing the author to use the Varian A-60 spectrometer equipped with the C-1024 computer unit, and to Dr. M. TAKEUCHI (JEOLCO, Paris) for the spectra recorded with the JEOL's instruments. Prof. J. PaAsivirTa and Mr. P. ÄYRÄs are gratefully acknowledged for the help in the double resonance experiments in the University of Turku. - This work has been financially supported by Neste $\mathrm{Oy}$ and the National Research Council for Sciences.

15 During the course of another investigation in this laboratory it has been found that $\left|{ }^{1} J_{\mathrm{NH}}\right|$ decreases about $0.5 \mathrm{~Hz}$ when the temperature raises from the melting point to the boiling point in ${ }^{15} \mathrm{~N}$-pyrrole liquid. 